\title{
Ensino de pronúncia: concepções de língua(gem) e de sujeito subjacentes ao Listen and Repeat ${ }^{1}$
}

\author{
Karin Quast \\ Universidade de Taubaté \\ mktostes@uol.com.br
}

\section{Resumo}

Em vista das mudanças conceituais ocorridas no campo de ensinoaprendizagem de línguas nas últimas décadas, nosso foco é o ensino de pronúncia, cujas propostas metodológicas parecem seguir uma trajetória mais lenta. Considerando que a prática de pronúncia inescapavelmente envolve a repetição, colocamos em discussão a própria noção de repetição, o papel conferido ao aluno em tal prática, como concebemos a relação sujeito-objeto de conhecimento e, consequentemente, as concepções de linguagem/sujeito subjacentes ao trabalho pedagógico. Observamos que a prática de pronúncia geralmente centra-se nos fonemas isolados, negligenciando-se os aspectos prosódicos, e vislumbramos as representações dos professores sobre pronúncia e de seu papel na produção de sentidos. Assim, para encaminharmos nossa reflexão, faremos uma análise microgenética de um dado utilizando o paradigma indiciário, apoiando-nos também nos relatórios do médico Jean Itard, que tentou ensinar a linguagem oral a um menino selvagem e nos trabalhos do Círculo de Bakhtin. O diálogo com as experiências pedagógicas de Itard pode parecer improvável, já que mais de dois séculos nos separam. Contudo, justamente por essa razão, parece-nos bastante produtivo para refletirmos sobre aspectos que ainda permeiam nossa prática. Prática, aliás, mais orientada por técnicas isoladas do que por uma abordagem teoricamente fundamentada.

Palavras-chave: Ensino de pronúncia. Aspectos prosódicos. Produção de sentidos. Concepção de linguagem. Jean Itard.

${ }^{1} \mathrm{O}$ presente artigo retoma alguns aspectos discutidos em nossa pesquisa de doutorado, que contou com o apoio da FAPESP.

Horizontes de Linguística Aplicada, ano 15, n. 1, 2016 


\begin{abstract}
Taking into consideration the conceptual changes that have occurred in language teaching in the past decades, our focus herein is pronunciation teaching, whose methodological proposals seem to follow a slower trajectory. Considering that pronunciation practice inescapably involves repetition, we approach the very notion of repetition, the role assigned to students in such practice, how we conceive the relation subject-object of knowledge and, consequently, the language/subject concepts that underlie the pedagogical work. Noting that pronunciation practice is normally centered on isolated phonemes, neglecting the prosodic aspects, it is possible to envision the teachers' representations about pronunciation and its role in the production of meaning/sense. Thus, in order to conduct our reflection, we will analyze some data using the evidential paradigm, which will be supported by the reports of Dr. Jean Itard, who tried to teach the oral language to a wild boy, as well as by the work of the Circle of Bakhtin. The dialogue with the pedagogic experiences of Itard may seem unlikely, as over two centuries set us apart. However, exactly for this reason, it seems quite productive in order to reflect upon aspects that still permeate our practice (more guided by isolated techniques than by a theoretically grounded approach).
\end{abstract}

Keywords: Pronunciation teaching. Prosodic aspects. Production of meaning. Language concept. Jean Itard.

\title{
1 Introdução
}

Neste trabalho buscamos problematizar alguns aspectos relacionados ao ensino de pronúncia tomando por base observações que temos feito ao longo dos anos em que lecionamos a disciplina de Fonologia no curso de Especialização em Língua Inglesa. Para encaminhar nossa discussão, embasamos em autores que tratam da questão da pronúncia, apoiando-nos, também, nos relatórios do médico Jean-Marc Gaspard Itard, que se encarrega da tarefa de tentar ensinar a linguagem oral a um "garoto selvagem" (a quem dá o nome de Victor), além de utilizar um dado de nossa pesquisa de doutorado. Nosso olhar sobre o tema ancora-se na perspectiva histórico-cultural, com ênfase aqui nos trabalhos do Círculo de Bakhtin.

A fala dos professores, as anotações em seus diários reflexivos, suas preocupações tanto em relação à própria pronúncia como à dos alunos e as atividades que relatam desenvolver ou que, em alguns 
momentos, foram por eles propostas em nossa disciplina, evidenciam que a maior preocupação centra-se nos aspectos segmentais da língua, isto é, os fonemas individuais. Não é raro, contudo, que o mesmo enfoque seja dado à pronúncia em grande parte dos livros didáticos e que pouco espaço seja dedicado aos aspectos prosódicos. Tal fato indica uma compreensão estreita, reducionista de pronúncia que ainda permeia o ensino de língua inglesa, bem como uma concepção estruturalista de linguagem (com influências do behaviorismo), uma vez que os aspectos suprassegmentais ou prosódicos, vinculados ao discurso, são geralmente negligenciados. Esses aspectos abrangem o tom, a intensidade (ou volume), a duração, a velocidade, as pausas, o acento, o ritmo, criando a entoação ${ }^{2}$. Incluímos também aqui a divisão dos enunciados em unidades de sentido.

Observamos que a maioria dos professores, atualmente, afirma adotar a abordagem Comunicativa de ensino ${ }^{3}$ ou embasar seu trabalho no sociointeracionismo, alguns inclusive desenvolvem um trabalho centrado em gêneros discursivos, sempre almejando o engajamento social e discursivo dos alunos, a ampliação de seus modos de ação e participação/inserção em diferenciadas práticas sociais, orientada à cidadania crítica. No entanto, o trabalho com pronúncia não parece seguir essa diretriz. Verificamos que independentemente da abordagem de ensino ou perspectiva teórica que se diz adotar, a prática ainda centra-se em torno de técnicas e exercícios que remontam ao método audiolingual e à perspectiva behaviorista de ensino-aprendizagem. Mas, como veremos a seguir, podemos voltar um pouco mais no tempo e verificar que nossa prática muitas vezes assemelha-se à prática clínica.

${ }^{2}$ No campo de pronúncia geralmente usa-se o termo "entoação", embora "entonação" também seja encontrado na literatura. Usaremos aqui o termo "entoação" ao tratarmos de pronúncia e o termo "entonação" como geralmente se encontra na tradução das obras do Círculo de Bakhtin ao referirmos à entonação expressiva, emotivo-valorativa.

3 A abordagem Comunicativa, contudo, pauta-se em uma perspectiva psicológica cognitivista e uma concepção de linguagem de viés instrumental e funcional, visando meramente o desenvolvimento de habilidades e competências comunicativas, ou seja, a linguagem é tida como instrumento de comunicação.

Horizontes de Linguística Aplicada, ano 15, n. 1, 2016 
Dessa forma, ao contrário de outros aspectos no processo de ensino-aprendizagem da língua estrangeira, não parece haver, no trabalho com pronúncia, uma preocupação com bases teóricas que o fundamentem. Tal fato, por sua vez, ilustra como o desenvolvimento da pronúncia parece ser concebido, isto é, basta ouvir e repetir... repetir... repetir. É inegável que a repetição tem um papel importante na aprendizagem de línguas, mas que tipo de repetição propomos? $\mathrm{O}$ que compreendemos por repetição? O que está envolvido na repetição?

Tomaremos, pois, para fins de nossa discussão, os relatórios de Jean Itard (1774-1838), que no início dos anos 1800 toma para si a incumbência de ensinar a linguagem oral a um menino selvagem, para refletirmos sobre o que entendemos por linguagem e sua apropriação, sobre as atividades que propomos e o papel dos alunos nesse processo, especialmente no que tange à pronúncia. Um diálogo com as experiências pedagógicas de Itard pode parecer uma ideia excêntrica devido aos séculos que nos separam, em virtude de seu trabalho ser mais discutido no campo da Educação - em especial, na educação de surdos. Também por acreditarmos que não compartilhamos as mesmas posições epistemológicas, a mesma concepção de sujeito e de linguagem, nem por concebermos da mesma forma como se dá a relação do sujeito com o objeto de conhecimento. Entretanto, acreditamos que é exatamente por meio desse contraste que algumas facetas de nossa prática pedagógica tornam-se mais reveladoras.

\section{Itard e Victor: o desenvolvimento da linguagem oral}

O caso do "garoto selvagem" (Victor de Aveyron) tem sido bastante discutido e tornou-se bem conhecido após François Truffaut lançar o filme L'infant sauvage em 1969. Com base nos minuciosos relatórios de Itard ${ }^{4}$, Truffaut tenta reconstituir a trajetória da educação de Victor, que foi encontrado na floresta, na região do Aveyron, no sul

\footnotetext{
${ }^{4} \mathrm{O}$ primeiro, um Mémoire, escrito em 1801 após nove meses de trabalho: $D a$ educação de um homem selvagem ou dos primeiros desenvolvimentos físicos e morais do jovem Selvagem do Aveyron. O segundo, publicado em 1807: Relatório feito a Sua Excelência o Ministro do Interior sobre os novos desenvolvimentos e o estado atual do Selvagem do Aveyron.
}

Horizontes de Linguística Aplicada, ano 15, n. 1, 2016 
da França, no final do século XVIII, parecendo ter por volta de 12-13 anos. Não usava vestimentas, locomovia-se andando de quatro, alimentava-se de raízes, batatas e castanhas e era mudo (apesar de não parecer ser surdo nem ter qualquer problema fisiológico que o impedisse de falar), emitindo apenas alguns grunhidos e sons guturais.

Ele é enviado a Rodez (capital do Aveyron), sendo então examinado pelo abade e botânico Bonnaterre (1751-1804), que escreve um relatório (publicado em 1800 em Paris), no qual detalha o estado do garoto, seus sentidos, sua fala, seus hábitos diários, seu comportamento. Após um período, o garoto é enviado ao Instituto Nacional de Surdos-Mudos - que havia sido criado em Paris, em 1785, pelo Abade de l'Epée (1712-1778) -, e dirigido naquela época pelo Abade Sicard (1742-1822). Lá um jovem médico demonstra grande interesse pelo caso do garoto: Jean-Marc Itard. A despeito de opiniões contrárias, inclusive a de seu mestre Pinel (que havia examinado e observado o menino durante o período no Instituto e concluído que não era possível obter sucesso em educá-lo ou socializá-lo, comparando-o a idiotas internados em hospícios), Itard acreditava em um prognóstico mais positivo para seu desenvolvimento físico e mental e decide tomar a responsabilidade por sua educação e inseri-lo na sociedade.

Para realizar seu intuito, Itard - que se contrapõe à noção de ideias inatas cartesianas - procura utilizar o conhecimento das Ciências disponíveis em sua época (Metafísica e Medicina). Seu trabalho é influenciado pelas ideias de Locke e, especialmente Condillac. Busca então despertar, educar, os sentidos do garoto. Porém, vale salientar o lugar privilegiado que a linguagem ocupa em sua linha de trabalho. A linguagem não servia somente para comunicar desejos, intenções. Isso Victor conseguia realizar muito bem com sua "linguagem de ação", ou seja, por meio de gestos e ações. A linguagem era considerada por Condillac como um pré-requisito para o desenvolvimento da cognição; as ideias estariam ligadas aos signos arbitrários, linguísticos.

Itard lança-se em árdua empreitada propondo cinco objetivos básicos para educar Victor: (1) interessá-lo pela vida social; (2) despertar sua sensibilidade nervosa, ou aprimorar os cinco sentidos; (3) fornecer-lhe novas necessidades a fim de ampliar o espectro de suas ideias; (4) ensiná-lo a falar por meio da imitação e movido pela necessidade; (5) exercitar as operações da mente. Nosso foco recai 
sobre como ele procede para ensinar os fonemas a Victor, como parte de seus procedimentos para ensinar-lhe a linguagem oral.

Ao usar um modelo clínico (ao contrário de um modelo sócioantropológico, por exemplo, que toma em consideração a cultura e a comunidade), Itard busca primeiramente despertar os cinco sentidos do garoto, que considera estarem dormentes. No tocante à linguagem oral, ele elabora vários métodos para aprimorar a capacidade auditiva do menino, expondo-o a uma variedade de sons, pedindo-lhe que os reproduzisse. Tenta torná-lo sensível aos sons da fala humana, já que são sons aos quais não estava habituado, levando-o a distinguir e produzir as cinco vogais. Entretanto, se por um lado Victor demonstrava certo desenvolvimento em relação à percepção dos sons, continuava mudo. As dificuldades de Victor são explicadas por Itard com base na fisiologia da criança e na competência que estaria presente em toda criança e que Victor teria perdido: a capacidade de imitar 5 .

A imitação, aliás, parece ainda ser considerada a "mola propulsora" no caso do desenvolvimento da pronúncia. Embora atualmente a noção de inteligibilidade internacional, ou seja, compreender e se fazer compreender (JENKINS, 2000), seja muito discutida no ensino de língua inglesa (dado que o objetivo de se obter uma pronúncia semelhante à do nativo mostrou-se ser irreal para aqueles que começam a aprender a LE quando jovens ou adultos), nos momentos em que a pronúncia recebe atenção em sala de aula, os professores esperam que seus alunos tenham uma pronúncia "perfeita". A pronúncia "perfeita", no entanto, parece resumir-se aos fonemas individuais ou às palavras isoladas e seria alcançada por meio da imitação/repetição.

Certamente a repetição é necessária. Os exercícios para o trato fonoarticulatório no sentido de conseguir produzir fonemas que não existem na nossa matriz, a língua mãe, são necessários. Contudo, ao se oferecer um modelo para o aluno seguir, muitos acreditam que este consegue ouvi-lo exatamente da forma como foi produzido e produzir

5 "Esta [a criança] não sabe nada; mas possui num grau eminente a suscetibilidade de aprender tudo; tendência inata à imitação; flexibilidade e sensibilidade excessivas de todos os órgãos; mobilidade incessante da língua; consistência quase gelatinosa da laringe (...).”(ITARD, 1801/2000, p. 157).

Horizontes de Linguística Aplicada, ano 15, n. 1, 2016 
uma cópia exata. Repete-se quantas vezes for necessário, esperando-se que o aluno, finalmente, consiga reproduzir fielmente aquele som (o que poucas vezes ocorre quando lidamos com jovens e adultos, frustrando tanto o aluno quanto o professor). Aparentemente, mesmo quando se trata de jovens e adultos, parte-se do mesmo princípio que Itard, ou seja, seríamos dotados de um "organismo que não pode não apre(e)nder” (LAJONQUIÈRE, 2000, p. 108).

Todavia, por que os resultados são tão desapontadores inclusive quando o aluno está motivado, deseja aprender, não se sente intimidado, envergonhado, não possui problemas com a cultura da língua sendo aprendida etc. nem teme perder sua identidade? Parece que nos esquecemos de alguns "pequenos detalhes" como: (1) o aparelho fonoarticulatório do jovem e adulto é diferente daquele da criança; (2) a conceituação dos fonemas, da cadência da língua, da entoação, foi desenvolvida em torno da primeira língua (L1), levandonos a interpretar e produzir novos "sons" à luz da L1, ou seja, tudo será interpretado à luz das categorias fonético-fonológicas desenvolvidas na L1. Não é um mero processo de reprodução. Ao mesmo tempo, existe, poderíamos dizer, um "exercício físico" na produção dos sons. Ao deparamos com fonemas que não existem na nossa língua e cuja produção envolve movimentos que não estamos acostumados a realizar, é necessário que nosso aparelho fonador "aprenda" a realizar tais fonemas. Contudo, isso não depende de mera repetição, mas de conscientização acerca do que fazemos para produzir determinado fonema.

Dessa forma, atividades centradas meramente na repetição, sem um trabalho de conscientização/conceituação de aspectos fonético-fonológicos não é suficiente para o desenvolvimento da pronúncia. Nesse ponto, poderíamos aprender um pouco com Itard, que vai, por exemplo, sensibilizando Victor e demonstrando como os sons são produzidos, o que está envolvido na produção de cada fonema, levando-o a sentir o lugar e maneira de articulação de cada 'som'.

Assim, lá estão o professor e o aluno em frente um do outro, cada um caretando mais que o outro, ou seja, imprimindo aos músculos dos olhos, da testa, da boca, do maxilar, movimentos de toda espécie; concentrando pouco a pouco suas experiências nos músculos dos lábios e, após ter 
Ensino de pronúncia: concepções de linguagem...

insistido muito tempo no estudo dos movimentos dessa parte carnuda do órgão da fala, submetendo enfim a língua aos mesmos exercícios, porém muito mais diversificados e continuados por muito tempo. (ITARD, 1806/2000, p. 215)

No entanto, se por um lado poderíamos aprender com as experiências de Itard, no sentido de conscientizarmos nossos alunos acerca de como os fonemas são realizados (ou seja, explorar o trato vocal, conscientizá-los sobre a passagem ou bloqueio do ar, sobre a abertura do maxilar, do local em que a língua se posiciona etc.) por outro, parte de nossos exercícios parece estar voltada a pessoas com problemas articulatórios. Entretanto, nossos alunos não sofrem de problemas articulatórios, eles não precisam ser tratados ou curados de suas inadequações - eles precisam, sim, aprender a como conceituar os sons que não estão presentes em seu repertório (cf. FRASER, 2001 para detalhes).

Desse modo, uma concepção estreita de pronúncia, limitada aos fonemas individuais cuja prática muito se assemelha às práticas de Itard $^{6}$ e desconexa, sem vínculo com as outras atividades realizadas em sala, acaba levando a resultados desencorajadores, desmotivadores, infrutíferos. Inclusive os jogos são muitas vezes usados isoladamente, apenas como uma forma mais agradável ou motivadora de "treinar" a pronúncia (fonemas).

Os resultados obtidos por Itard, apesar de ele depositar grande confiança em sua série de exercícios para preparar o "órgão da palavra" a imitar os sons da língua, foram também desapontadores, levando-o a desistir de tentar ensinar Victor a falar, abandonando o garoto, como afirma, "a um mutismo incurável” (id. ibid., p. 216). Mas, se por um lado Victor não aprende a falar, por outro bem compreende as diferentes nuances de entoação. A entoação (ou os aspectos prosódicos), contudo, é um dos aspectos mais negligenciados no ensino de pronúncia.

Ainda há algo mais que Itard desconsidera e também, nós professores, muitas vezes o fazemos. Na ânsia de "ensinar", de cumprir

${ }^{6}$ É quase impossível não nos lembrarmos de alguma aula de inglês ao vermos Victor no filme de Truffaut emitindo sons frente a uma vela acesa e fazermos uma associação com a prática de pronúncia do fonema $/ \theta /$.

Horizontes de Linguística Aplicada, ano 15, n. 1, 2016 
um programa, na ânsia de "ensinar" aquilo que os alunos não precisam nem desejam, esquecemos de prestar atenção ao que eles desejam ou ao que trazem para a sala de aula e que se relaciona às experiências deles - emocionalmente vividas, carregadas de entonações, valores, posições, vozes. Itard nota, mas não presta muita atenção, a uma palavra e um enunciado de Victor (e, portanto, não os explora), produzidos espontaneamente e que são carregados de ento(n)ação. Esses não foram ensinados, mas ouvidos em sua relação com a governanta de Itard, Madame Guérin, que o ajudava a cuidar do menino. Madame Guérin usava a expressão “Oh Dieu! Oh Dieu!", que Victor então reproduzia, embora com certa diferença na pronúncia. Ele também repetia o som gli (=lhi), como uma forma de se referir à Julie, filha de Madame Guérin, que a visitava todas as semanas.

De acordo com Banks-Leite (2011, p. 169), '[t]udo leva a crer que tais "produções", eram consideradas como criancices (enfantillages) que são permitidas na relação de Victor com outros, como Sra. Guérin, mas cuja importância era vista como nula para uma verdadeira aprendizagem junto ao médico-pedagogo.' $E$ todavia nós vemos indícios de apropriação da língua, no sentido de tomar para si, diferentemente da situação de aprendizagem da língua .

O termo apropriação, conforme concebido por Smolka (2000) envolve "pertencer ou participar nas práticas sociais", que, por sua vez, são historicamente construídas e nas quais os processos de significação, as "diferentes possibilidades de produção de sentido" e as posições e modos de participação dos sujeitos são colocados em evidência. Entretanto, continua a autora, apropriação não significa e nem sempre coincide com adequado ou pertinente ao outro. E a indagação de Smolka possui relação com a história de Victor e merece também uma reflexão por parte dos professores: '[...] não existem outros modos de aprender, de participar, de desenvolver capacidades, recursos, estratégias de ação, que podem se tornar "apropriados" (próprios, mesmo que idiossincráticos; e pertinentes mesmo que diferentes)?'

E esse brincar com a língua que Victor demonstra, deveria também ser permitido em sala de aula. O encantamento (ou mesmo o estranhamento) com esses novos sons, especialmente para as crianças, poderia ser explorado, abraçado em sala de aula. 
Portanto, se Itard é criticado por mais proceder como um adestrador (cf. LAJONQUIÈRE, 2000) e vemos procedimentos semelhantes sendo usados com nossos alunos, não estaríamos fazendo o mesmo com eles? E, ainda, conhecer a gramática, a sintaxe, as diferentes funções da linguagem, os diferentes gêneros do discurso e saber pronunciar as palavras "corretamente" garante que nossos alunos sejam compreendidos oralmente e consigam compreender seu interlocutor? Permite-lhes a inserção/participação em diferenciadas práticas sociais, em diferentes eventos discursivos?

\section{A pronúncia no foco do aluno}

Para refletirmos acerca da abrangência do tema pronúncia, trazemos aqui um episódio em que a pronúncia torna-se alvo/objeto de atenção a partir da dúvida de um aluno. Embora muitos outros aspectos sejam dignos de atenção e discussão, nosso foco aqui será especificamente a pronúncia.

Sinais de transcrição:

$T$ (professora); PA, MA e GU (os alunos)

Pausas: /

Quebras bruscas: |

Comentários da pesquisadora [ ]

Segmentos inaudiveis (...)

A professora havia trazido um texto que fora planejado como prática de compreensão oral, mas teve que lê-lo devido a problemas com o equipamento de som. Logo que inicia a leitura, é interrompida por um dos alunos. Essa intervenção altera, reestrutura a dinâmica da aula/discurso e a atividade se transforma:

1. T: Good evening, ladies an' gentlemen, welcome to 'What's my job?' We have|

2. PA: Teacher licença posso pergunta(r) uma coisa? / sempre quis sabe(r) esse ladies and? 
3. T: Gentlemen

4. MA: Gentlemen

5. PA: Gentlemen

6. MA: gentlemen $\mathrm{G}-\mathrm{E}-\mathrm{N}-\mathrm{T}-\mathrm{L}-\mathrm{E}-\mathrm{M}-\mathrm{E}-\mathrm{N}$

7. GU: gentlemen start your engines [olhando para o chão e usando entoação típica de jogos]

8. $\mathrm{T}$ : $\mathrm{G}-\mathrm{E}-\mathrm{N}-\mathrm{T}-\mathrm{L}-\mathrm{E}-\mathrm{M}-\mathrm{E}-\mathrm{N}$ [soletra enquanto

9. GU: Gentleman escreve no quadro]

10. MA: ladies an' gentlemen [com entoação de programa de TV]

11. PA: gentlemen (...)

12. T: ladies an' gentlemen

13. MA: (...)

14. GU: aqueles joguinhos de joguinho de corrida / gentlemen start your engines / fala desse jeito assim né?

15. MA: (...) que o cara fala ladies an' gentlemen

16. T: Yeah ladies an' gentlemen

Nesse episódio vislumbramos os diferentes momentos de "aproximação" dos alunos em relação ao segmento ladies and gentlemen. Eles se detêm no significado da palavra e na pronúncia em nível segmental. A pronúncia da palavra vai permeando todo o episódio. Aparentemente, a preocupação central é a pronúncia, tendo em vista o número de repetições. Contudo, a preocupação com a pronúncia não está desvinculada da significação! E, ao mesmo tempo em que se detêm na pronúncia da palavra, os alunos trazem a curva melódica desse segmento, ou seja, o aspecto prosódico é por eles salientado e parece estar amalgamado ao(s) significado(s)/sentido(s) do segmento. O segmento, portanto, não é tomado como uma frase impessoal da língua, como a palavra-código; ele não tem apenas um significado compartilhado, mas ao trazerem-no como algo vivenciado em suas práticas sociais, em contextos diferentes, parece produzir diferentes sentidos. Esse segmento os impactou, significou. Esse segmento nos remete, pois, à experiência emocionalmente vivida (perezhivanie), conforme afirma Smolka (2006, p. 107): 
Ensino de pronúncia: concepções de linguagem...

É falando das relações com/no meio que Vygotsky destaca a perezhivanie, isto é, a experiência, sentimento, experiência emocional, aquilo que se vai fazendo enquanto formação da personalidade, que se repete uma e outra vez, que implica o entretecimento do funcionamento mental e das emoções em modos socialmente constituídos de os indivíduos estarem no mundo. Experiência é resultante daquilo que impacta e é compreendido, significado, pela pessoa. Há um aspecto compreensivo, apreciativo, valorativo nos sentidos da situação vivida. Não existe experiência sem significação. (...) Falar de experiência é falar de corpo/sujeito afetado pelo outro/signo (...). É falar da vida impregnada de sentido.

Os alunos trazem a entoação empregada nos diferentes contextos em que esse segmento é utilizado. Sob uma perspectiva bakhtiniana, eles trazem a voz do(s) outro(s) e revelam a dialogicidade fundante da linguagem. Cada enunciado tem seu propósito específico. Em um, temos o tom solene que nos impele a silenciarmos e prestarmos atenção e, no outro, o tom mais energético, incitando-nos a iniciar a ação no jogo. Esses enunciados circulam em diferentes esferas da atividade humana; diferentes esferas de comunicação. Cada um deles tem sua entoação característica, que é, portanto, de natureza social (VOLOSHINOV, 1926). Cada enunciado, também demarca, digamos assim, nossas posições, os lugares que podemos ocupar na interação, as relações de poder e, orienta, regula, organiza nossas ações. Cada enunciado representa a realidade a partir de um ponto de vista, revela um quadro axiológico.

Vemos, também, que esse segmento tem um sentido vivencial, ressonâncias concernentes à vida, como afirma Bakhtin/Voloshinov:

$\mathrm{Na}$ realidade, não são palavras o que pronunciamos ou escutamos, mas verdades ou mentiras, coisas boas ou más, importantes ou triviais, agradáveis ou desagradáveis etc. A palavra está sempre carregada de um conteúdo ou de um sentido ideológico ou vivencial. É assim que compreendemos as palavras e somente reagimos àquelas que despertam em nós ressonâncias ideológicas ou 
concernentes à vida (BAKHTIN/VOLOSHINOV, 1999, p. 95).

Se nós, professores, esquecemo-nos de que os aspectos suprassegmentais (ou os prosodemas ${ }^{7}$ ), ligados ao discurso, atuam na produção de sentidos ${ }^{8}$, esses alunos indicam como a entoação pode estar vinculada aos significados/sentidos apre(e)ndidos, (re)significados, transformados, produzidos.

Muitas vezes esquecemo-nos também de que a palavra "não é um objeto", nunca a encontramos "como uma palavra neutra da língua, isenta das aspirações e avaliações de outros ou despovoada das vozes dos outros" (BAKHTIN, 2002, p. 203). Talvez esse tenha sido um dos problemas de Itard, tentar ensinar as palavras como objetos, desvinculadas de situações reais vivenciadas por Victor.

Toda palavra já nos vem carregada de acentos emotivovolitivos, de tons apreciativos, de índices e julgamentos de valor e esses compõem a significação. Nas palavras de Bakhtin/Voloshinov (1999, p. 132), “[s]em acento apreciativo, não há palavra”. Conforme esclarece Authier-Revuz (2004, p. 35-36), retomando Bakhtin,

Toda palavra "remete a um contexto, ou a vários, nos quais viveu sua existência socialmente subjugada". Ela "chega a seu próprio contexto, vinda de outro contexto, penetrada pelo sentido dado por outros". As palavras são "carregadas", "ocupadas", "habitadas", "atravessadas", por discursos, é o que Bakhtin designa "saturação da linguagem [...] socialmente significante [...] por intenções $e$ acentos determinados".

Assim, no processo de apropriação da palavra de outrem, nós também apropriamo-nos da ento(n)ação expressiva, como ilustram esses alunos. Ao mesmo tempo, a retomada da palavra do outro implica uma tomada de posição (ou uma atitude responsivo-ativa) por

\footnotetext{
${ }^{7}$ Cf. Mateus, 2005; Martins, 2000; Dubois et alii, 1978.

${ }^{8}$ Alguns autores defendem que os aspectos suprassegmentais podem causar mais problemas de compreensão do que inadequações na produção dos fonemas, como Gilbert, 2008; Fraser, 2001; Celce-Murcia et al, 1996;
} Nakashima, 2006, dentre outros.

Horizontes de Linguística Aplicada, ano 15, n. 1, 2016 
Ensino de pronúncia: concepções de linguagem...

parte do locutor, que julga-a apropriada para atingir seu intuito discursivo.

A entoação, portanto, não está desvinculada da produção de significados/sentidos, não é um elemento que simplesmente se agrega ou não (ou um item opcional) e que, portanto, como muitos parecem acreditar, deveria ser alvo de ensino (se porventura o for) apenas quando os alunos atingem o nível intermediário ou avançado.

Segundo Gonçalves,

[...] a Entoação participa diretamente da expressão do conteúdo de um enunciado, em nível de importância semelhante ao das unidades sintáticas e morfolexicais. Várias evidências podem ser depreendidas a partir do que foi exposto: (1) os enunciados contêm um terceiro nível de organização (a Prosódia), ao lado da Sintaxe e da Semântica; (2) os principais expoentes desse módulo da Gramática são, entre outros, o Acento, a Entonação e o Ritmo; (3) a interpretação semântica de um enunciado depende tanto de sua configuração sintática quanto da Entonação a ela conferida, haja vista que (3b) uma mesma sequência linear de elementos pode ter o sentido levemente modificado (nuançado) pela atribuição de proeminência prosódica a um de seus constituintes; (4) a Focalização, na qualidade de categoria discursivo-pragmática que expressa contraste (cf. Gonçalvez, 1997), pode ser veiculada por expedientes de natureza suprassegmental, unicamente. [...] (GONÇALVES, 1999).

Assim, a proeminência prosódica, no sentido, por exemplo, de chamar a atenção para uma nova informação, para algo que queremos enfatizar, contrastar, intensificar, é importante no discurso. Existem ainda outros aspectos relacionados à entoação, a saber: (1) as funções gramaticais - que nós professores geralmente indicamos por cinco tons (ou as variações de altura), ou seja, ascendente, descendente, ascendente-descendente, descendente-ascendente ou plano (flat) - que indicam se o enunciado é uma pergunta, uma afirmação, uma ordem; se é conclusivo, se estamos realizando um contraste etc.; (2) as funções atitudinais, indicando dúvida, certeza, reserva, preocupação, sarcasmo, ironia, obstinação, desdém, condescendência, rispidez etc. Percebemos, Horizontes de Linguística Aplicada, ano 15, n. 1, 2016 
pois, a importância da entoação no discurso, podendo, ainda, demarcar fronteiras entre enunciados, indicar a continuação de um tópico conversacional, sinalizar a inicialização de novo tópico, induzir o interlocutor a responder ou desencorajá-lo a responder, demarcar a alternância dos sujeitos, dentre outros aspectos (cf. CHUN, 2002).

Além desses pontos e também dos aspectos relacionados a estados emocionais, atitudinais (incluindo as atitudes valorativas e a atitude em relação ao interlocutor, ou seja, a posição social ou hierárquica, sua importância, os conhecimentos que possui etc.) e as intenções que a entoação deixa perceber, existe outro aspecto que muito pode afetar a relação com o interlocutor. Dependendo da entoação, ou seja, quanto mais invariável e uniforme (flat) esta for, podemos soar desinteressados, entediados, distantes, ríspidos ou rudes, sem que seja esse nosso estado/humor ou intenção. Ou seja, nosso interlocutor pode depreender de nossa entoação uma apreciação valorativa diferente de nossa real posição emotivo-valorativa (seja em relação ao tema do enunciado, seja em relação a nosso interlocutor).

\section{Considerações finais}

Enfim, indagamos então se nosso trabalho com pronúncia é coerente com a abordagem metodológica e a perspectiva teórica que afirmamos embasar nossa prática docente.

Se nosso foco recai somente sobre aspectos segmentais, nossa concepção de língua(gem) seria a de sistema abstrato, neutro (não comportando juízos de valor, perspectivas, crenças, visões de mundo, ideologias), representacional, autônomo, imutável, com significados/sentidos já dados, prontos, acabados. Diferentemente da visão da língua(gem) como processo, (inter)ação, atividade organizadora, transformadora, significativa, dialógica, polifônica, polissêmica; constitutiva e estruturante do plano mental e do sujeito; processo e produto da atividade humana; dinâmica, criadora, significante, multifuncional, heterogênea; axiologicamente determinada.

Estaríamos, ao mesmo tempo, atendo-nos meramente a frases, sentenças estereotipadas, funções? Como bem indica Voloshinov 
(1926) uma palavra é vazia do ponto de vista semântico; qualquer entoação pode ser usada ou pode agir sobre uma palavra. O sistema da língua não possui entonação expressiva, acentos apreciativos ou de valor, somente o enunciado (BAKHTIN, 2000, p. 310). E a entonação expressiva "é um dos recursos para expressar a relação emotivovalorativa do locutor com o objeto do seu discurso" (id. ibid., p. 309). A expressividade, por sua vez, decorre de nossa intenção discursiva (id. ibid., p. 310-311).

A entoação só pode ser compreendida profundamente quando estamos em contato com os julgamentos de valor presumidos por um dado grupo social, qualquer que seja a extensão deste grupo. A entoação sempre está na fronteira do verbal com o não-verbal, do dito com o não-dito. Na entoação, o discurso entra diretamente em contato com a vida. E é na entoação sobretudo que o falante entra em contato com o interlocutor ou interlocutores - a entoação é social por excelência. Ela é especialmente sensível a todas as vibrações da atmosfera social que envolve o falante. (VOLOSHINOV, 1926, p. 10)

Destacamos que estamos a analisar enunciados e não frases, orações, palavras neutras. Neutras no sentido de não comportarem, por si sós, um juízo de valor, podendo estar a serviço de qualquer juízo de valor (BAKHTIN, 2000, p. 309). O enunciado "é um elo real na cadeia da comunicação verbal, no interior de uma dada esfera da realidade humana ou da vida cotidiana" (id. ibid., p. 307). Ele tem um autor e um (ou mais) interlocutor(es). Responde a outros enunciados e sempre aguarda uma atitude responsiva ativa. Os enunciados, ao contrário das palavras e orações (unidades da língua), não são neutros, eles sempre possuem uma intencionalidade, dirigem-se ao outro e expressam uma atitude emotivo-valorativa para com o objeto do discurso que se realiza na entonação expressiva. Como afirma Ducrot (1988, p. 14), falar é "(...) construir y tratar de imponer a los otros una especie de aprehensión argumentativa de la realidad".

Podemos novamente refletir com Bakhtin (ibid., p. 311), quando ele afirma que 
Não alinhavamos as palavras, passando de uma para outra. Pelo contrário, é como se preenchêssemos um todo com as palavras úteis. Alinhavam-se palavras na primeira fase do estudo de uma língua estrangeira, e isso sempre se deve a um método errado na direção do trabalho.

Ao utilizar, portanto, a repetição sem um processo de conscientização e de conceituação dos aspectos segmentais e prosódicos não estaríamos tratando nossos alunos como meros repetidores ou adestrando-os (retomando aqui críticas feitas a Itard)? Nossa linha de trabalho é monológica, prescritiva ou dialógica, discursiva? Usamos atividades em que a entonação expressiva tenha lugar? Nossos alunos têm oportunidades de tomar a palavra, de se assumirem como autores de seus enunciados? Eles recebem um "lugar de enunciação" " (ao contrário de Victor)?

E, ainda, como concebemos a significação, a produção de sentidos, ao ignorarmos os elementos prosódicos? Como se dá então a relação do aluno com a língua(gem) e com o outro sem a entoação? Os alunos, geralmente, desejam se expressar na outra língua. Mas como expressar, quer seja, gostos, hábitos, preferências ou ideias, valores, opiniões; como relatar, expor, narrar, criar, brincar, discutir, analisar, avaliar, criticar, significar, argumentar, (re)construir identidades sem a entonação expressiva, emotivo-valorativa?

Os alunos do episódio analisado neste estudo evidenciam que ladies and gentlemen não é tomado como frase da língua, mas como enunciado(s). Enunciados concretos e por eles vivenciados, vinculados a contextos socioculturais, pertencentes a determinado gênero do discurso. Enunciados que fazem parte da memória, das práticas sociais deles, enunciados impregnados de sentido experiencial e com entoação expressiva que lhes é própria.

\footnotetext{
${ }^{9}$ Termo adaptado de Lajonquière (2000), que o usa no campo da Psicanálise, sendo aqui pensado no campo discursivo.
}

Horizontes de Linguística Aplicada, ano 15, n. 1, 2016 
Ensino de pronúncia: concepções de linguagem...

\section{Referências}

AUTHIER-REVUZ, Jacqueline. Entre a transparência e a opacidade: um estudo enunciativo do sentido. Porto Alegre: EDIPUCRS, 2004.

BAKHTIN, Mikhail M./VOLOSHINOV, Valentin N. Marxismo $e$ filosofia da linguagem. Tradução de Michel Lahud e Yara Frateschi Vieira. 9. ed., São Paulo: Hucitec, 1999[1929].

BAKHTIN, Mikhail M. Problemas da poética de Dostoiévski. Tradução Paulo Bezerra. 3. ed. Rio de Janeiro: Forense Universitária, 2002.

BAKHTIN, Mikhail M. Estética da criação verbal. Tradução de Maria Ermantina Galvão G. Pereira. 3. ed. São Paulo: Martins Fontes, 2000.

BANKS-LEITE, Luci. Linguagem, conhecimento e desenvolvimento humano: três estudos. Tese (Livre-docência em Psicologia) Faculdade de Educação, Universidade Estadual de Campinas, Campinas, 2011.

CELCE-MURCIA, Marianne; BRINTON, Donna M.; GOODWIN, Janet. Teaching pronunciation: a reference for teachers of English to speakers of other languages. Cambridge: Cambridge University Press, 1996.

CHUN, Dorothy M. Discourse intonation in L2: from theory and research to practice. Amsterdam: John Benjamins, 2002.

DUBOIS, Jean et alii. Dicionário de lingüística. Trad. do francês de EP. Barros et. al. São Paulo: Cultrix, 1978.

DUCROT, Oswald. Polifonia y argumentación. Cali, Colombia: Impresora Feriva Ltda, 1988. 
FRASER, Helen. Teaching pronunciation: $a$ handbook for teachers and trainers. Canberra: Department of Education Training and Youth Affairs, 2001. Disponível em:

<http://www.eslmania.com/teacher/esl_teaher_talk/Pronunciation_Han dbook.pdf >. Acesso em 20 jan. 2015.

GILBERT, Judy B. Teaching pronunciation: using the prosody pyramid, 2008. Disponível em: <http://www.cambridge.org/other_files/downloads/esl/booklets/Gilbert -Teaching-Pronunciation.pdf >. Acesso em 08 jun. 2015.

GONÇALVES, Carlos A. O fenômeno da focalização e a interface fonologia-sintaxe. DELTA, v. 15 n. 2, p. 319-342, 1999.

ITARD, Jean. (1801). Da educação de um homem selvagem ou dos primeiros desenvolvimentos físicos e morais do jovem Selvagem do Aveyron. Tradução de Luci Banks-Leite. In: GALVÃO, Isabel (Org.). A educação de um selvagem: as experiências pedagógicas de Jean Itard. São Paulo, Cortez, 2000. p. 123-177.

. (1806). "Relatório feito a Sua Excelência o Ministro do Interior sobre os novos desenvolvimentos e o estado atual do Selvagem do Aveyron". Tradução de Luci Banks-Leite. In: GALVÃO, Isabel (Org.). A educação de um selvagem: as experiências pedagógicas de Jean Itard. São Paulo, Cortez, 2000. p. 179-229.

JENKINS, Jennifer. The phonology of English as an international language: new models, new norms, new goals. Oxford, England: Oxford University Press, 2000.

LAJONQUIÈRE, Leandro de. Itard Victor!!! Ou do que não deve ser feito na educação. In: BANKS-LEITE, Luci; GALVÃO, Isabel. A educação de um selvagem. As experiências pedagógicas de Jean Itard. São Paulo: Cortez, 2000. p. 105-116.

MATEUS, Maria Helena M. Estudando a melodia da fala: traços prosódicos e constituintes prosódicos. Palavras: Revista da 
Ensino de pronúncia: concepções de linguagem...

Associação de Professores de Português, n. 28, p. 79-98, 2005. Disponível em: <http://www.iltec.pt/pdf/wpapers/2004-mhmateusprosodia.pdf $>$. Acesso em 18 jan. 2015.

MARTINS, Nilce Sant'Anna. Introdução à estilística: a expressividade da língua portuguesa. 3. ed. São Paulo: T. A. Queiroz, 2000.

NAKASHIMA, Toru. Intelligibility, suprasegmentals, and L2 pronunciation instruction for EFL Japanese learners. Fukuoka Kyoiku Daigaku Kiyo, v. 55, n. 1, p. 27-42, 2006. Disponível em: <https://libopac.fukuokaedu.ac.jp/dspace/bitstream/10780/14/1/1003.pdf>. Acesso em 26 mai. 2015.

SMOLKA, Ana Luiza B. O (im)próprio e o (im)pertinente na apropriação das práticas sociais. Cadernos CEDES, v. 20, n. 50, p. 2640, abr. 2000.

VOLOSHINOV, Valentin N. [1926]. Discurso na vida e discurso na arte. Tradução de Carlos Alberto Faraco e Cristovão Tezza, para uso didático, com base na tradução inglesa de I. R. Titunik ("Discourse in life and discourse in art - concerning sociological poetics"). In: Freudism, New York: Academic Press, 1976.

Recebido em: 24/08/2015 Aceito em: 20/11/2015

Title: Pronunciation teaching: language and subject concepts underlying the "Listen and Repeat" practice 